Artículo original

\title{
Rendimiento diagnóstico de la secuenciación de genes de hipercolesterolemia familiar en sujetos con hipercolesterolemia primaria
}

\author{
Itziar Lamiquiz-Moneo ${ }^{\mathrm{a}}$, Fernando Civeira, ${ }^{\mathrm{a}, \mathrm{b}, *}$, Rocío Mateo-Gallego ${ }^{\mathrm{a}, \mathrm{c}}$, Martín Laclaustra $^{\mathrm{a}, \mathrm{d}}$, \\ Belén Moreno-Franco ${ }^{\mathrm{e}, \mathrm{f}}$, María Teresa Tejedor ${ }^{\mathrm{g}}$, Lourdes Palacios ${ }^{\mathrm{h}}$, César Martín ${ }^{\mathrm{i}}$ y Ana Cenarro ${ }^{\mathrm{a}, \mathrm{j}, \mathrm{k}}$
}

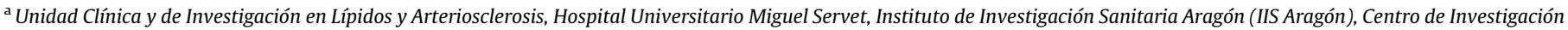
Biomédica en Red de Enfermedades Cardiovasculares (CIBERCV), Zaragoza, España

${ }^{\mathrm{b}}$ Departamento de Medicina, Psiquiatría y Dermatología, Universidad de Zaragoza, Zaragoza, España

${ }^{\mathrm{c}}$ Departamento de Fisiatría y Enfermería, Universidad de Zaragoza, Zaragoza, España

${ }^{\mathrm{d}}$ Fundación Agencia Aragonesa para la Investigación y el Desarrollo (ARAID), Zaragoza, España

e Departamento de Microbiología, Medicina Preventiva y Salud Pública, Universidad de Zaragoza, Zaragoza, España

${ }^{\mathrm{f}}$ Unidad de Prevención Cardiovascular, Hospital Universitario Miguel Servet, Instituto de Investigación Sanitaria Aragón (IIS Aragón), Zaragoza, España

${ }^{\mathrm{g}}$ Departamento de Anatomía, Embriología y Genética, Universidad de Zaragoza, Zaragoza, España

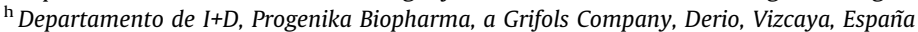

i Instituto Biofisika (UPV/EHU, CSIC), Leioa, Vizcaya, España

${ }^{\mathrm{j}}$ Departamento de Bioquímica y Biología Molecular, Universidad del País Vasco, UPV/EHU, Bilbao, España

${ }^{\mathrm{k}}$ Instituto Aragonés de Ciencias de la Salud (IACS), Zaragoza, España

Historia del artículo:

Recibido el 15 de diciembre de 2019

Aceptado el 14 de mayo de 2020

\section{Palabras clave:}

Prevalencia HF

Mutación en genes candidatos

$L D L R$

PCSK9

STAP1

Lipoproteína (a)

Criterios de sospecha de HF

\section{RE S U M E N}

Introducción y objetivos: Nuestro objetivo fue aproximar la prevalencia de mutaciones en los genes candidatos de hipercolesterolemia familiar (HF) en una población española de mediana edad, y determinar el valor predictivo de los criterios clínicos de sospecha de HF en la detección de mutaciones causales.

Métodos: Se seleccionaron individuos mayores de 18 años no relacionados de la cohorte Estudio de Salud de los Trabajadores de Aragón (AWHS) con colesterol unido a lipoproteínas de baja densidad $(\mathrm{cLDL})>$ percentil 95, con enfermedad cardiovascular prematura o con cLDL $>130 \mathrm{mg} / \mathrm{dl} \mathrm{con}$ tratamiento hipolipemiante, asumiendo que al menos una de las características estará presente en todos los individuos con HF. En estos participantes se secuenciaron los genes LDLR, APOB, PCSK9, APOE, STAP1 y LDLRAP1 mediante secuenciación masiva.

Resultados: De 5.400 individuos del AWHS, 4.514 tenían datos lipídicos y registro farmacológico hipolipemiante completo, 255 participantes (5,65\%) cumplían los criterios de sospecha de HF, 24 de ellos (9,41\%) fueron diagnosticados de hiperlipoproteinemia(a) y 16 (6,27\% de los secuenciados) presentaron alguna mutación causal en genes candidatos: 12 participantes portaban 11 alelos patogénicos diferentes en $L D L R$ y 4 participantes portaban una mutación patogénica en PCSK9. Las concentraciones de cLDL $>220 \mathrm{mg} / \mathrm{dl}$ y el cLDL $>130 \mathrm{mg} / \mathrm{dl}$ a pesar del tratamiento con estatinas mostraron la mayor asociación con la presencia de mutación ( $p=0,011)$.

Conclusiones: Nuestros resultados muestran que la prevalencia española de HF es 1:282 y sugieren que una concentración de cLDL elevado, y niveles altos de cLDL a pesar de la terapia con estatinas son los mejores predictores para un diagnóstico genético positivo de HF.

(c) 2020 Sociedad Española de Cardiología. Publicado por Elsevier España, S.L.U. Todos los derechos reservados.

Diagnostic yield of sequencing familial hypercholesterolemia genes in individuals with primary hypercholesterolemia

A B S T R A C T

Introduction and objectives: Our objective was to approximate the prevalence of mutations in candidate genes for familial hypercholesterolemia (FH) in a middle-aged Spanish population and to establish the predictive value of criteria for clinical suspicion in the detection of causative mutations.

Methods: Unrelated individuals aged $\geq 18$ years from the Aragon Workers' Health Study (AWHS) with high low-density lipoprotein cholesterol (LDL-C) and clinical suspicion of FH (participants with LDL-C concentrations above the 95th percentile, participants with premature cardiovascular disease and/or participants with high LDL-C [130 mg/dL] under statin therapy), assuming that any participant with FH exhibits at leats 1 trait, were selected and the LDLR, APOB, PCSK9, APOE, STAP1 and LDLRAP1 genes were sequenced by next generation sequencing technology.

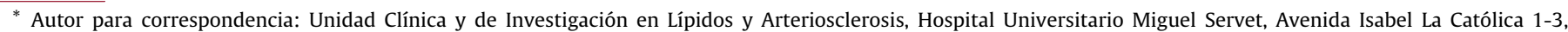
50009 Zaragoza, España.

Correo electrónico: civeira@unizar.es (F. Civeira).
} 
Results: Of 5400 individuals from the AWHS, 4514 had complete data on lipid levels and lipid-lowering drugs, 255 participants (5.65\%) met the criteria for suspicion of FH, 24 of them (9.41\%) were diagnosed with hyperlipoproteinemia(a), and 16 (6.27\% of those sequenced) were found to carry causative mutations in candidate genes: 12 participants carried 11 different pathogenic $L D L R$ alleles and 4 participants carried 1 pathogenic mutation in PCSK9. LDL-C concentrations $>220 \mathrm{mg} / \mathrm{dL}$ and LDL-C $>130 \mathrm{mg} / \mathrm{dL}$ despite statin therapy showed the strongest association with the presence of mutations $(P=.011)$.

Conclusions: Our results show that the prevalence of $\mathrm{FH}$ in Spain is 1:282 and suggest that the combination of high untreated LDL-C and high levels of LDL-C despite statin therapy are the best predictors of a positive $\mathrm{FH}$ genetic test.

(c) 2020 Sociedad Española de Cardiología. Published by Elsevier España, S.L.U. All rights reserved.

\section{Abreviaturas \\ AWHS: Aragon Workers' Health Study (Estudio de Salud de los Trabajadores de Aragón) \\ cLDL: colesterol unido a las lipoproteínas de baja densidad EC: enfermedad coronaria \\ HF: hipercolesterolemia familiar}

\section{INTRODUCCIÓN}

La hipercolesterolemia familiar (HF) es un trastorno genético caracterizado por unas concentraciones plasmáticas de colesterol total muy altas, debidas al aumento del colesterol unido a las lipoproteínas de baja densidad (cLDL), con un gran riesgo de enfermedad coronaria (EC) prematura ${ }^{1}$. Tradicionalmente, la HF se ha descrito como una enfermedad monogénica con una transmisión autosómica codominante y una prevalencia estimada de alrededor de 1:500 en la población general ${ }^{2}$. Sin embargo, hay algunas discrepancias por lo que respecta a la prevalencia de la HF. Estudios recientes han puesto de manifiesto que la HF clínica probablemente sea más frecuente de lo que se había pensado, 1:217 en el estudio Copenhagen General Population ${ }^{3}$. Un diagnóstico temprano es crucial en la HF, ya que se ha demostrado que el tratamiento hipolipemiante reduce drásticamente la $\mathrm{EC}^{4}$, sobre todo si el tratamiento se inicia en una fase temprana de la vida ${ }^{5}$. No obstante, en la población general la HF está infradiagnosticada e infratratada ${ }^{6}$.

El diagnóstico clínico de la HF se basa en una alta concentración plasmática de cLDL, antecedentes familiares de hipercolesterolemia, antecedentes personales y familiares de EC prematura y signos de depósito de colesterol, como xantomas tendinosos y arco corneal prematuro. Estos parámetros se evalúan a menudo con puntuaciones clínicas aplicando los criterios Make Early Diagnosis to Prevent Early Death (MEDPED), la modificación del MEDPED de la Dutch Lipid Clinic Network (DLCN) o los criterios del Simon Broome Register Group (SBRG) ${ }^{7}$. Se ha demostrado que estos criterios clínicos muestran una intensa asociación con el diagnóstico genético $^{8,9}$. Sin embargo, estos criterios incluyen una información que no siempre está disponible o requiere cierto conocimiento experto, y se emplean la mayoría de las veces en unidades especializadas $^{6,10}$. Por esta razón, y con objeto de mejorar el diagnóstico, el European Atherosclerosis Society Consensus Panel recomienda unos criterios de sospecha, previos al diagnóstico clínico: a) en los adultos, un colesterol total en plasma $>310 \mathrm{mg} / \mathrm{dl}$ $0>$ percentil 95 correspondiente a la edad y el sexo en el país; $b$ ) en los niños, una concentración de colesterol total en plasma > $230 \mathrm{mg} / \mathrm{dl} \mathrm{o}>$ percentil 95 correspondiente a la edad y al sexo en el país; c) EC prematura (a una edad $<55$ años los varones $\mathrm{y}<60$ años las mujeres); d) xantomas tendinosos; e) muerte súbita por EC prematura de un familiar (a una edad $<55$ años los varones $\mathrm{y}<$ 60 años las mujeres $)^{6}$. Sin embargo, no se ha validado la utilidad clínica de estos criterios de sospecha.
El diagnóstico genético es el patrón de referencia en una enfermedad monogénica y se recomienda encarecidamente su uso en la $\mathrm{HF}^{11}$. La HF tiene origen en mutaciones de diversos genes: $L D L R$, que codifica para el receptor de las lipoproteínas de baja densidad (LDL); $A P O B$, que codifica para la apolipoproteína $\mathrm{B}^{12}, \mathrm{y}$ PCSK9, para la enzima proproteína convertasa subtilisina/kexina tipo $9^{13}$. Se ha identificado un nuevo locus causante de HF: la mutación p.(Leu167del) en el gen $A P O E^{14}$. Además, varias mutaciones en el gen STAP1, que forma parte de la familia del adaptador de transducción de señal, se han asociado con la $\mathrm{HF}^{15}$, si bien recientemente se ha puesto en duda el papel de este gen ${ }^{16,17}$. Por otra parte, las concentraciones de lipoproteína(a) [Lp(a)] en plasma son un rasgo heredable que se asocia con un aumento del riesgo de $\mathrm{EC}$, y se ha descrito que la hiperlipoproteinemia(a) [hiperLpa(a)] es una causa frecuente de hipercolesterolemia autosómica dominante ${ }^{18}$. El conocimiento de la mutación causal confirma el diagnóstico, establece un pronóstico, facilita los exámenes de detección sistemática en la familia y mejora la adherencia del paciente al tratamiento ${ }^{19}$. La presencia de mutaciones patógenas en los genes causantes de la HF en pacientes con un diagnóstico clínico de HF implica un aumento sustancial del riesgo de $\mathrm{EC}^{20}$, por lo que las pruebas genéticas permiten la identificación de las personas que tienen el mayor riesgo de EC de entre las que presentan hipercolesterolemia. Sin embargo, estas pruebas genéticas tienen también ciertas dificultades, como son la complejidad genética de la enfermedad, con la implicación de varios genes, miles de mutaciones diferentes, algunas de las cuales tienen una trascendencia patógena incierta, y la poca disponibilidad del análisis genético en algunos sistemas de salud.

El objetivo del presente estudio es estimar la prevalencia de las mutaciones en genes candidatos en una población de mediana edad de España mediante criterios de sospecha clínica, y analizar su valor predictivo respecto a la presencia de mutaciones causales.

\section{MÉTODOS}

\section{Participantes}

Se seleccionó a los individuos evaluados de la población del Aragon Workers' Health Study (AWHS). El AWHS es un estudio de cohorte longitudinal de los factores de riesgo cardiovascular y de la ateroesclerosis subclínica que se lleva a cabo en 5.400 trabajadores de la fábrica Opel España, situada en Aragón (España), y que han sido objeto de seguimiento desde $2009^{21}$. Para esta publicación se estudió a los individuos no emparentados de edad $\geq 18$ años del AWHS de los que se dispusiera de determinaciones anuales o bianuales desde 2009. Se utilizaron los siguientes criterios para seleccionar a las personas con sospecha clínica de HF: a) participantes con concentraciones de cLDL no tratadas $>$ percentil 95 de la población española estratificada según la edad y el $\operatorname{sexo}^{22}$ en como mínimo 2 determinaciones; b) participantes con EC prematura (edad $<55$ años los varones $\mathrm{y}<60$ años las mujeres) en la situación inicial; c) participantes en tratamiento con estatinas y con cLDL $>130 \mathrm{mg} / \mathrm{dl}$ en al menos 
2 determinaciones, $\mathrm{y} d$ ) participantes con concentraciones de cLDL no tratadas > percentil 95 de la población española en tan solo 1 determinación pero también el cLDL $>130 \mathrm{mg} / \mathrm{dl}$ en tratamiento con estatinas. Los criterios de exclusión fueron la presencia basal o durante el seguimiento de causas secundarias de hipercolesterolemia, como obesidad grave (índice de masa corporal [IMC] $>35$ ), diabetes mellitus tipo 2 mal controlada $\left(\mathrm{HbA}_{1 \mathrm{c}}>8 \%\right)$, enfermedad renal con tasa de filtrado glomerular $<30 \mathrm{ml} / \mathrm{min} \mathrm{y} / \mathrm{o}$ macroalbuminuria, hepatopatía (alanina transaminasa $>3$ veces el límite superior de la normalidad), hipotiroidismo (tirotropina $>6 \mathrm{mUI} / \mathrm{l}$ ), embarazo, enfermedades autoinmunitarias y el tratamiento con inhibidores de proteasa. Se definió al sujeto con hiperLp(a) como el individuo con sospecha de HF y una concentración de $\mathrm{Lp}(\mathrm{a})>50 \mathrm{mg} / \mathrm{dl}$, pero concentraciones de cLDL ajustadas por la Lp(a) normales ( $<$ percentil 95 de la población española $)^{22}$.

Todos los participantes dieron su consentimiento informado por escrito y el estudio fue aprobado por el Comité de Ética de Investigación Clínica de Aragón (CEICA).

Se llevó a cabo una evaluación de los factores de riesgo cardiovascular, los antecedentes personales y familiares de enfermedad cardiovascular, la toma de medicamentos con efectos en el metabolismo lipídico y los parámetros antropométricos de todos los participantes en la situación inicial y luego a intervalos anuales o bianuales durante el seguimiento.

\section{Análisis de lípidos}

Se realizaron análisis de lípidos y lipoproteínas en muestras de plasma en EDTA obtenidas tras una noche o al menos $10 \mathrm{~h}$ en ayunas, a intervalos anuales o bianuales desde el año 2009. Se incluyeron las determinaciones realizadas hasta 2015. Se determinaron las concentraciones de colesterol total y de triglicéridos con métodos enzimáticos estándares. El colesterol unido a lipoproteínas de alta densidad (cHDL) se determinó directamente con una reacción enzimática de la colesterol oxidasa (UniCel DxC 800; Beckman Coulter, Inc., Estados Unidos). El cLDL se calculó con la fórmula de Friedewald. Los valores lipídicos de los participantes que estaban en tratamiento hipolipemiante se ajustaron en función del tratamiento con estatinas ${ }^{23}$. Ninguno de ellos estaba een tratamiento con inhibidores de la PCSK9. La Lp(a) se determinó mediante nefelometría cinética IMMAGE (Beckman Coulter Inc., Estados Unidos). Se obtuvieron los valores de cLDL ajustados por la $\mathrm{Lp}$ (a) restando a la concentración de cLDL calculada con la fórmula de Friedewald la concentración de $\operatorname{Lp}\left(\right.$ a) dividida por $3^{24,25}$.

\section{Análisis genético}

Se aisló el ADN genómico de sangre total mediante métodos estándares. Mediante secuenciación de nueva generación con la plataforma SeqProLipo Platform (Progenika Biopharma Grifols, España), de secuenciaron los genes LDLR (NM_000527.4), PCSK9 (NM_174936.3), APOE (NM_000041.3), STAP1 (NM_0121108.3) y LDLRAP1 (NM_015627.2) y los exones 26 y 29 del gen APOB (NM_000384.2), que contienen el código del lugar de unión $L D L R$. Dicha plataforma incluye mutaciones puntuales, reordenaciones grandes y variaciones en el número de copias.

Para evaluar la patogenicidad de las variantes identificadas, se utilizó SIFT ${ }^{26}$, PolyPhen-2 ${ }^{27}$, Mutation Taster $^{28}$ y PredictSNP ${ }^{29}$. El efecto de las variantes en los posibles lugares de corte y empalme se predijo con FruitFly ${ }^{30}$. Para comparar las frecuencias de las variantes identificadas en los participantes en el estudio y en la población general, se compilaron las frecuencias alélicas de las variantes identificadas procedentes del 1000 Genomes Project ${ }^{31}$ y los ExAc Browser Data ${ }^{32}$. Las variantes raras se definieron como las variantes genéticas con una frecuencia $<1 \%$ de la población general. Una variante rara se definió como variante causal cuando ya estaba asociada con la HF y como variante posiblemente patógena cuando la predicción del análisis bioinformático la clasificaba como patógena.

\section{Análisis estadístico}

Los análisis se realizaron con el programa informático de cálculo estadístico R versión 3.5.0 $0^{33}$. La distribución de las variables se analizó con la prueba de Shapiro. Las variables cuantitativas con una distribución normal se expresan en forma de media \pm desviación estándar y se analizaron con una prueba de ANOVA. Las variables con una distribución asimétrica se expresan como mediana [intervalo intercuartílico] y se analizaron con la prueba de KruskalWallis. Las variables cualitativas se expresan en forma de porcentajes y se analizaron con la prueba de la $\chi^{2}$. El nivel de significación estadística se estableció en $\mathrm{p}<0,05$. Se utilizó una regresión binaria logística para determinar el mejor diagnóstico con los criterios de la European Atherosclerosis Society, tomando la presencia de una mutación en genes candidatos como variable dependiente.

\section{RESULTADOS}

\section{Participantes en el estudio que cumplían los criterios clínicos de HF}

De los 5.400 individuos incluidos en el AWHS, se dispuso de la información necesaria para evaluar los criterios de inclusión y exclusión de 4.514. Se excluyó a un total de 886 individuos porque los datos lipídicos registrados no eran completos, tenían menos de 2 paneles lipídicos completos y/o datos incompletos sobre el uso de fármacos hipolipemiantes. De los 4.514 participantes, 255 (5,65\%) cumplían los siguientes criterios de inclusión (que no son mutuamente excluyentes): a) 127 participantes presentaban concentraciones de cLDL no tratadas > percentil 95 de la población española en al menos 2 determinaciones; $b$ ) 21 tenían una EC prematura en la situación inicial (edad $<55$ años los varones y $<60$ las mujeres); c) 39 tenían una concentración de cLDL $>130 \mathrm{mg} / \mathrm{dl}$ en como mínimo 2 determinaciones pese al tratamiento con estatinas, y d) 113 tenían una concentración de cLDL sin tratamiento > percentil 95 de la población española en 1 determinación y también un cLDL $>130 \mathrm{mg} / \mathrm{dl}$ en al menos otra ocasión en tratamiento con estatinas (figura 1).

Los participantes con concentraciones de CLDL altas a pesar del tratamiento con estatinas y los que tenían una EC en la situación inicial eran de más edad y tenían un IMC más alto que el resto de los participantes. Los participantes que estaban en tratamiento con estatinas y tenían concentraciones de cLDL altas a pesar del tratamiento farmacológico y aquellos con cLDL elevado en 1 determinación y también concentraciones de cLDL altas en tratamiento con estatinas presentaban unas concentraciones de colesterol total, cLDL y triglicéridos más altas que las de los demás participantes. Los participantes con una EC prematura tenían concentraciones de Lp(a) más altas. Los participantes con concentraciones altas de cLDL en como mínimo 2 determinaciones y que no tomaban ningún tratamiento hipolipemiante fueron el 93,7\% (tabla 1).

\section{Análisis genético}

En el análisis de secuenciación se identificaron 5.280 variantes en genes candidatos en los 255 participantes secuenciados (figura 1): a) 1.792 variantes en el gen $L D L R, 11$ de las cuales se han descrito como patógenas y ya asociadas con la HF; b) 249 variantes en el gen $A P O B$, aunque ninguna de ellas se ha descrito como patógena ni se ha asociado anteriormente con la HF; c) 1.697 variantes en el gen PCSK9, de las cuales solo 1 se ha descrito como patógena y ya asociada con la 


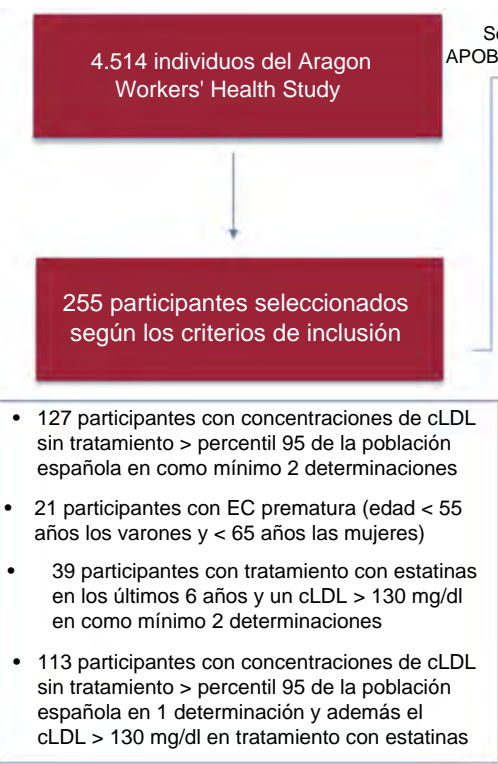

Secuenciación de los genes LDLR B, PCSK9, APOE, STAP1 y LDLRAP1

$\longrightarrow$

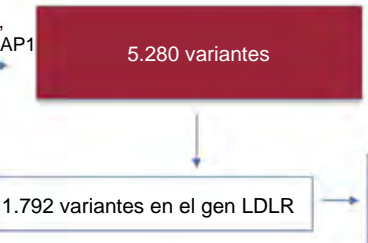

11 variantes patógenas 114 variantes no patógenas 1.667 polimorfismos

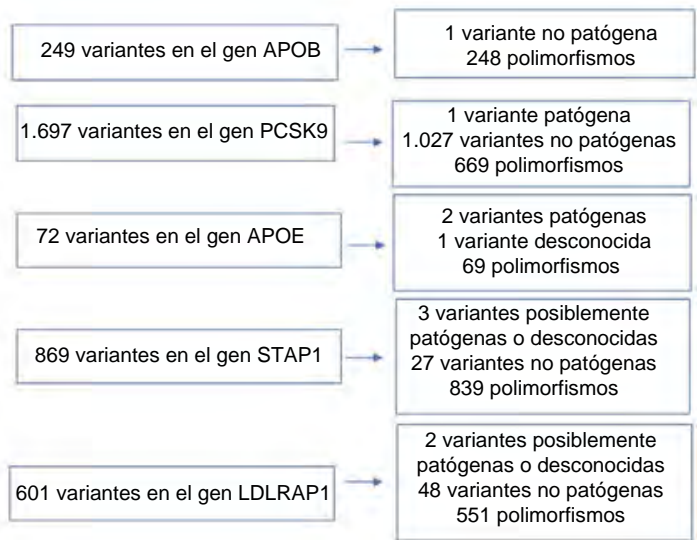

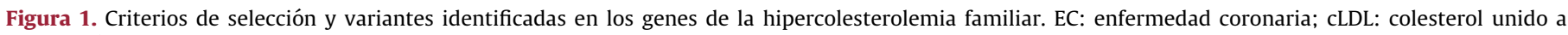
lipoproteínas de baja densidad.

Tabla 1

Características bioquímicas y clínicas basales y número de portadores de mutación según los criterios de selección

\begin{tabular}{|c|c|c|c|c|}
\hline & $\begin{array}{l}\text { Participantes con concentraciones de } \\
\text { cLDL sin tratamiento > percentil } \\
95 \text { de la población española en al } \\
\text { menos } 2 \text { determinaciones } \\
(n=127)\end{array}$ & $\begin{array}{l}\text { Participantes con EC } \\
\text { prematura (edad }<55 \text { años } \\
\text { los varones y }<60 \text { las } \\
\text { mujeres) } \\
(\mathrm{n}=21)\end{array}$ & $\begin{array}{l}\text { Participantes con } \\
\text { tratamiento con } \\
\text { estatinas en los últimos } \\
6 \text { años y cLDL }>130 \mathrm{mg} / \\
\text { dl en al menos } \\
2 \text { determinaciones } \\
(n=39)\end{array}$ & $\begin{array}{l}\text { Participantes con } \\
\text { concentraciones de cLDL } \\
\text { sin tratamiento > percentil } \\
95 \text { de la población } \\
\text { española en } \\
1 \text { determinación y además } \\
\text { cLDL > } 130 \mathrm{mg} / \mathrm{dl} \text { pese al } \\
\text { tratamiento con estatinas } \\
(n=113)\end{array}$ \\
\hline Edad (años) & $40,2 \pm 8,47$ & $48,0 \pm 4,59$ & $47,7 \pm 4,45$ & $46,4 \pm 5,23$ \\
\hline IMC & $26,8 \pm 3,11$ & $26,4 \pm 2,38$ & $28,2 \pm 2,89$ & $27,4 \pm 2,73$ \\
\hline Varones & $119(93,7)$ & $21(100)$ & $39(100)$ & $108(95,6)$ \\
\hline Colesterol total $(\mathrm{mg} / \mathrm{dl})$ & $318 \pm 57,4$ & $271 \pm 61,4$ & $352 \pm 48,6$ & $351 \pm 61,0$ \\
\hline$c L D L(\mathrm{mg} / \mathrm{dl})$ & $223 \pm 47,3$ & $177 \pm 45,7$ & $235 \pm 38,9$ & $239 \pm 48,6$ \\
\hline$c H D L(m g / d l)$ & $51,7 \pm 8,92$ & $49,0 \pm 8,34$ & $52,8 \pm 11,3$ & $53,6 \pm 9,57$ \\
\hline Triglicéridos $(\mathrm{mg} / \mathrm{dl})$ & $143[113-201]$ & $99,5[82,9-163]$ & $178[141-247]$ & $150[116-217]$ \\
\hline Apolipoproteína B ( $\mathrm{mg} / \mathrm{dl})$ & $135 \pm 29,1$ & $101 \pm 51,2$ & $120 \pm 22,1$ & $139 \pm 30,00$ \\
\hline Lipoproteína $(a)(\mathrm{mg} / \mathrm{dl})$ & $41,1[8,48-75,4]$ & $72,3[42,4-80,7]$ & $25,5[15,2-34,6]$ & $24,4[9,53-60,3]$ \\
\hline Glucosa $(\mathrm{mg} / \mathrm{dl})$ & $89,1 \pm 11,4$ & $94,6 \pm 27,3$ & $95,1 \pm 12,3$ & $90,5 \pm 12,4$ \\
\hline$H b A_{1 c}(\%)$ & $5,30[5,20-5,30]$ & $5,30[5,30-5,30]$ & $5,30[5,30-5,30]$ & $5,40[5,35-5,50]$ \\
\hline Insulina $(\mathrm{UI} / \mathrm{ml})$ & $5,50[3,58-7,60]$ & $4,10[3,60-7,10]$ & $5,30[4,10-7,13]$ & $5,70[3,95-9,20]$ \\
\hline \multicolumn{5}{|l|}{ Tratamiento con estatinas } \\
\hline Ninguno & $119(93,7)$ & $10(47,6)$ & $0(0)$ & $84(74,3)$ \\
\hline Intensidad baja & 0 & 0 & $6(15,4)$ & $5(5,95)$ \\
\hline Intensidad moderada & $7(5,52)$ & $10(47,6)$ & $31(79,5)$ & $22(19,5)$ \\
\hline Intensidad alta & $1(0,78)$ & $1(4,76)$ & $2(5,13)$ & $2(1,77)$ \\
\hline \multicolumn{5}{|l|}{ Mutación causal en genes candidatos } \\
\hline Ninguna & $114(89,8)$ & $20(95,2)$ & $36(92,3)$ & $103(91,2)$ \\
\hline Portadores de mutación en $L D L R$ & $8(6,30)$ & 0 & $2(5,55)$ & $9(7,96)$ \\
\hline Portadores de mutación en PCSK9 & $3(2,36)$ & $1(4,76)$ & 0 & 0 \\
\hline Portadores de mutación en STAP1 & $2(1,57)$ & 0 & $1(2,56)$ & $1(0,88)$ \\
\hline
\end{tabular}

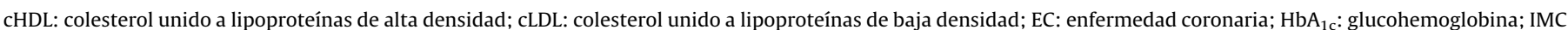
índice de masa corporal.

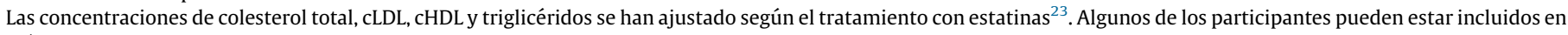
más de un grupo.

Los valores expresan $\mathrm{n}(\%)$, media \pm desviación estándar o mediana [intervalo intercuartílico]. 
Tabla 2

Variantes causales en genes candidatos identificadas en algunos de los pacientes de este estudio

\begin{tabular}{|c|c|c|c|c|c|c|c|c|c|c|c|}
\hline \multirow[t]{2}{*}{ Gen } & \multirow[t]{2}{*}{ SNV } & \multirow[t]{2}{*}{ Nucleótido } & \multirow{2}{*}{$\begin{array}{l}\text { Cambio de } \\
\text { aminoácido }\end{array}$} & \multirow[t]{2}{*}{ Portadores, n } & \multicolumn{4}{|c|}{ Análisis bioinformático } & \multirow[t]{2}{*}{ Var. Clin. } & \multirow[t]{2}{*}{ Frecuencia ExAc ${ }^{32}$} & \multirow{2}{*}{$\begin{array}{l}\text { Frecuencia } \\
1000 \mathrm{G}^{31}\end{array}$} \\
\hline & & & & & $\mathrm{SIFT}^{26}$ & POLYPHEN-2 $2^{27}$ & $\begin{array}{l}\text { Mutation } \\
\text { Taster }^{28}\end{array}$ & PredictSNP $^{29}$ & & & \\
\hline LDLR & rs879254375 & c. $-135 \mathrm{C}>\mathrm{G}$ & n. p. & 1 participante & n. p. & n. p. & n. p. & n. p. & Patógena & - & - \\
\hline LDLR & $\begin{array}{l}\text { rs774467219 } \\
\text { rs112029328 }\end{array}$ & $\begin{array}{l}\text { c. }[274 C>G \\
313+1 G>C]\end{array}$ & p.[Gln92Glu;NA] & 1 participante & $\begin{array}{l}\text { Tolerada } \\
(0,15)\end{array}$ & $\begin{array}{l}\text { Posiblemente } \\
\text { dañina }(0,736)\end{array}$ & $\begin{array}{l}\text { Nociva } \\
(0,510)\end{array}$ & $\begin{array}{l}\text { Neutra } \\
(0,252)\end{array}$ & Patógena & 0,0009715 & 0,001 \\
\hline$L D L R$ & rs121908026 & c. $530 \mathrm{C}>\mathrm{T}$ & p.(Ser177Leu) & 1 participante & $\begin{array}{l}\text { Nociva } \\
(0,01)\end{array}$ & $\begin{array}{l}\text { Probablemente } \\
\text { dañina }(0,999)\end{array}$ & $\begin{array}{l}\text { Nociva } \\
(0,896)\end{array}$ & Nociva $(0,000090)$ & Patógena & 8,958e-06 & - \\
\hline LDLR & rs879254692 & c. $826 \mathrm{~T}>\mathrm{G}$ & p.(Cys276Gly) & 1 participante & $\begin{array}{l}\text { Nociva } \\
(0)\end{array}$ & $\begin{array}{l}\text { Probablemente } \\
\text { dañina } \\
(0,969)\end{array}$ & $\begin{array}{l}\text { Nociva } \\
(0,856)\end{array}$ & Nociva $(0,000005)$ & Patógena & - & - \\
\hline LDLR & rs368657165 & c. $862 \mathrm{G}>\mathrm{A}$ & p.(Glu288Lys) & 1 participante & $\begin{array}{l}\text { Nociva } \\
(0,05)\end{array}$ & $\begin{array}{l}\text { Probablemente } \\
\text { dañina }(0,918)\end{array}$ & $\begin{array}{l}\text { Nociva } \\
(0,714)\end{array}$ & Nociva $(0,000018)$ & Patógena & 0 & - \\
\hline$L D L R$ & - & c.941-?_1845+?del & $\begin{array}{l}\text { Deleción de } \\
\text { exón } 7 \text { a exón } 12\end{array}$ & 1 participante & & & & & Patógena & & \\
\hline LDLR & rs773658037 & c. $1247 \mathrm{G}>\mathrm{A}$ & p.(Arg416Gln) & 1 participante & $\begin{array}{l}\text { Nociva } \\
(0,01)\end{array}$ & $\begin{array}{l}\text { Probablemente } \\
\text { dañina }(0,957)\end{array}$ & $\begin{array}{l}\text { Nociva } \\
(0,806)\end{array}$ & Nociva $(0,000045)$ & Patógena & 1,793e-05 & 0 \\
\hline$L D L R$ & rs755154048 & c. $1529 \mathrm{C}>\mathrm{T}$ & p.(Thr510Met) & 1 participante & $\begin{array}{l}\text { Nociva } \\
(0,02)\end{array}$ & $\begin{array}{l}\text { Posiblemente } \\
\text { dañina }(0,791)\end{array}$ & $\begin{array}{l}\text { Nociva } \\
(0,679)\end{array}$ & Nociva $(0,000013)$ & $\begin{array}{l}\text { Patógena/ } \\
\text { Probablemente } \\
\text { patógena }\end{array}$ & $8,952 \mathrm{e}-06$ & - \\
\hline LDLR & rs781362878 & c. $1586+5 G>A$ & n. p. & 1 participante & n. p. & n. p. & n. p. & n. p. & $\begin{array}{l}\text { Incierta/ } \\
\text { Patógena }\end{array}$ & 1,796e-05 & \\
\hline LDLR & rs137929307 & c. $1775 \mathrm{G}>\mathrm{A}$ & p.(Gly592Glu) & 2 participantes & $\begin{array}{l}\text { Nociva } \\
(0,01)\end{array}$ & $\begin{array}{l}\text { Probablemente } \\
\text { dañina } \\
(0,925)\end{array}$ & $\begin{array}{l}\text { Nociva } \\
(0,779)\end{array}$ & Nociva $(0,000015)$ & Patógena & $8,951 \mathrm{e}-05$ & - \\
\hline$L D L R$ & rs72658865 & c. $1816 \mathrm{G}>\mathrm{A}$ & p.(Ala606Thr) & 1 participante & $\begin{array}{l}\text { Nociva } \\
(0,02)\end{array}$ & $\begin{array}{l}\text { Posiblemente } \\
\text { dañina } \\
(0,5)\end{array}$ & $\begin{array}{l}\text { Nociva } \\
(0,550)\end{array}$ & Nociva $(0,000034)$ & $\begin{array}{l}\text { Probablemente } \\
\text { benigna/Incierta }\end{array}$ & $8,952 \mathrm{e}-06$ & - \\
\hline PCSK9 & rs371488778 & $\begin{array}{l}\text { c.60_65dup } \\
\text { GCTGCT }\end{array}$ & p.(Leu22_Leu23dup) & 4 participantes & n. p. & n. p. & n. p. & Nociva $(0,000002)$ & Incierta/ Patógena & 0,002144 & - \\
\hline
\end{tabular}

n. p.: no procede. 
Tabla 3

Características clínicas y perfil lipídico según la causa principal de la hipercolesterolemia

\begin{tabular}{|c|c|c|c|c|c|c|}
\hline & $\begin{array}{l}\text { Participantes sin } \\
\text { mutación en genes } \\
\text { candidatos y sin } \\
\text { hiperLp(a) }(n=211)\end{array}$ & $\begin{array}{l}\text { Participantes portadores } \\
\text { de mutaciones en } L D L R \\
(\mathrm{n}=12)\end{array}$ & $\begin{array}{l}\text { Participantes } \\
\text { portadores de } \\
\text { mutaciones en } \\
\text { PCSK9 }(n=4)\end{array}$ & $\begin{array}{l}\text { Participantes } \\
\text { portadores de } \\
\text { mutaciones en } \\
\text { STAP1 }(\mathrm{n}=4)\end{array}$ & $\begin{array}{l}\text { Participantes con } \\
\operatorname{hiperLp}(a)(n=24)\end{array}$ & $\mathrm{p}$ \\
\hline Edad (años) & $44,3 \pm 7,53$ & $44,3 \pm 6,89$ & $43,0 \pm 9,09$ & $37,8 \pm 13,7$ & $41,7 \pm 9,43$ & 0,242 \\
\hline IMC & $27,3 \pm 2,83$ & $26,5 \pm 3,38$ & $28,9 \pm 3,41$ & $26,0 \pm 1,36$ & $25,7 \pm 3,46$ & 0,061 \\
\hline Varones & $207(96,3)$ & $11(91,7)$ & $4(100)$ & $4(100)$ & $21(87,5)$ & 0,356 \\
\hline Colesterol total (mg/dl) & $323 \pm 53,8$ & $406 \pm 97,8$ & $321 \pm 13,2$ & $304 \pm 24,7$ & $298 \pm 41,9$ & $<0,001$ \\
\hline $\mathrm{cHDL}(\mathrm{mg} / \mathrm{dl})$ & $52,1 \pm 9,96$ & $56,2 \pm 6,77$ & $53,8 \pm 11,8$ & $53,5 \pm 9,00$ & $55,2 \pm 10,2$ & 0,440 \\
\hline cLDL (mg/dl) & $220 \pm 38,6$ & $297 \pm 91,8$ & $221 \pm 18,8$ & $208 \pm 26,0$ & $221 \pm 28,8$ & $<0,001$ \\
\hline cLDL ajustado por $\mathrm{Lp}(\mathrm{a})(\mathrm{mg} / \mathrm{dl})$ & $218 \pm 37,3$ & $296 \pm 92,6$ & $220 \pm 19,6$ & $207 \pm 25,9$ & $164 \pm 26,9$ & $<0,001$ \\
\hline Triglicéridos (mg/dl) & $172 \pm 80,3$ & $132 \pm 37,3$ & $126 \pm 27,3$ & $111 \pm 23,2$ & $119 \pm 52,1$ & 0,004 \\
\hline Lipoproteína(a) (mg/dl) & $20,3[8,25-41,0]$ & $17,2[13,9-20,6]$ & $4,50[3,20-6,00]$ & $4,50[3,13-7,90]$ & $80,0[68,8-114]$ & $<0,001$ \\
\hline
\end{tabular}

cHDL: colesterol unido a lipoproteínas de alta densidad; cLDL: colesterol unido lipoproteínas de baja densidad; IMC: índice de masa corporal; Lp(a): lipoproteína(a).

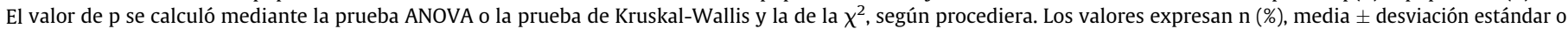
mediana [intervalo intercuartílico].

HF; d) 72 variantes en el gen $A P O E, 2$ de las cuales ya asociadas con la hiperlipoproteinemia tipo III; e) 869 variantes en el gen STAP1, 3 de las cuales se han descrito como posiblemente patógenas mediante el análisis bioinformático, y f) 601 variantes en el gen LDLRAP1, 2 de las cuales se han clasificado como posiblemente patógenas mediante el análisis bioinformático. Sin embargo, ninguna de estas 2 variantes posiblemente patógenas del gen LDLRAP1 estaba presente en homocigosis, condición esta que se ha descrito como necesaria para causar una hipercolesterolemia.

El porcentaje de mutaciones en genes candidatos fue similar en los diversos grupos; sin embargo, los participantes con concentraciones de cLDL altas en como mínimo 2 determinaciones fueron los que presentaron un porcentaje más alto de mutaciones causales, que superó el $8 \%$ de los casos (tabla 1). Un total de 12 pacientes eran portadores de 11 alelos patógenos distintos en heterocigosis en el gen $L D L R: 1$ de ellos con una variante causal ubicada en la región del promotor (c.-135C $>$ G); 7 de ellos tenían una variante causal situada en regiones codificadoras, con lo que producían un cambio de aminoácido (c.530C $>\mathrm{T}, \quad$ c.826T $>\mathrm{G}, \quad$ c.862G $>$ A, c.1247G $>\mathrm{A}$, c.1529C $>$ T, c.1775G $>$ A y c.1816G $>$ A); 1 de ellos con una variante causal, situada en una región intrónica, que daba lugar a un cambio de corte y empalme alternativo (c.1586+5G $>$ A); 1 alelo tenía 2 variantes causales situadas en cis: $($ c. $274 \mathrm{C}>\mathrm{G})$ y $($ c. $313+1 \mathrm{G}>\mathrm{C})$ y 1 de ellos tenía una reordenación grande (c.941-?_1845+?del). Todos estos casos se han descrito como patógenos mediante el análisis bioinformático y ya se habían descrito como causa de $\mathrm{HF}^{34-40}$. Tan solo 1 paciente era portador de una variante rara en el exón 26 del gen $A P O B,(c .10621 \mathrm{~A}>\mathrm{G})$. Sin embargo, esta variante no se ha asociado anteriormente como causa de HF, se clasificó como benigna en el análisis bioinformático y no parece que afecte a la estructura de la región de unión. Se halló que 5 pacientes eran portadores de 2 variantes raras en el gen PSCK9 (c.60_65dup GCTGCT y c.743G >A), y solo la primera se ha asociado anteriormente con la HF. De estos pacientes, 4 eran portadores de un indel en el marco de lectura c.60_65dupGCTGCT, que se ha descrito como de patogenicidad incierta o probable por Clin $\operatorname{Var}^{41}$ y Garcia et al. ${ }^{42}$. También 5 pacientes eran portadores de 3 variantes raras en el gen $A P O E$, ninguna descrita antes como causa de HF. Una de ellas nunca se ha asociado con ninguna hiperlipemia y el análisis bioinformático la clasificó como desconocida en (c.335C $>$ A). Las otras 2 variantes (c.460C $>A$, c. $487 \mathrm{C}>\mathrm{T}$ ) se hallaron en 3 y 1 participantes respectivamente. Ambas variantes ya estaban asociadas con la hiperlipoproteinemia de tipo III $^{43,44}$. De los 4 pacientes portadores de 3 variantes raras desconocidas en el gen STAP1, 2 eran portadores de 1 variante situada en la región 5' (c.-60A >G) y los otros 2 eran portadores de 2 variantes diferentes situadas en regiones de codificación, con lo que producían una sustitución de aminoácido (c.619G >A y c.803T >C). Ninguna de estas variantes se ha asociado anteriormente con la HF. Se halló que 2 pacientes eran portadores de 2 variantes raras y desconocidas en heterocigosis en el gen LDLRAP1, y 1 de ellas producía un cambio de aminoácido (c.605C >G), mientras que la otra podía afectar al corte y empalme (c.748-7C >G). Sin embargo, las mutaciones en el gen LDLRAP1 tan solo producen hipercolesterolemia cuando se encuentran en homocigosis (tabla 2 y tabla 1 del material adicional).

\section{Hiperlipoproteinemia(a)}

En 24 (9,41\%) participantes con criterios de sospecha de HF a causa de un cLDL > percentil 95, cuando se analizó el colesterol transportado en la $\mathrm{Lp}(\mathrm{a})$, los valores de cLDL dejaron de ser > percentil 95. Ninguno de estos participantes con hiperLp(a) era portador de una mutación patógena en genes candidatos para la HF.

\section{Características según el análisis genético}

En la tabla 3 se muestran las características clínicas y el perfil lipídico según la clasificación genética, con la inclusión de los participantes con hiperLp(a). Los participantes portadores de mutaciones en el gen $L D L R$ fueron los que mostraron las concentraciones más altas de colesterol total y cLDL. Además, los portadores de mutaciones en el gen PCSK9 presentaban unas

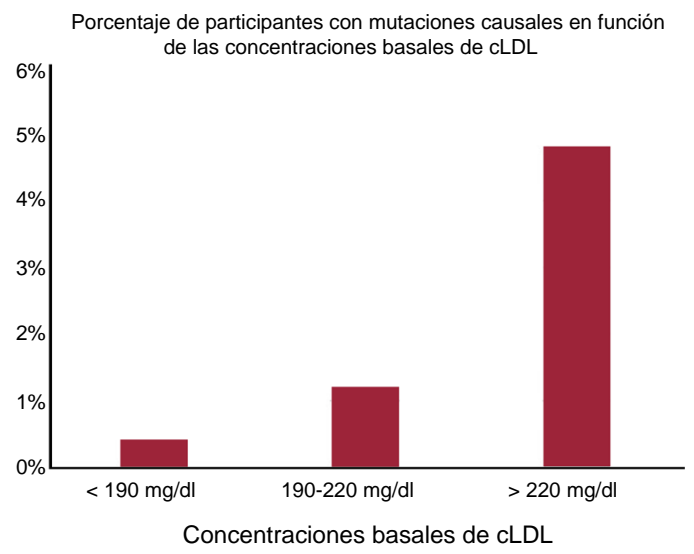

Figura 2. Porcentaje de participantes con mutaciones causales en función de las concentraciones basales de cLDL. cLDL: colesterol unido a lipoproteínas de baja densidad. 
Tabla 4

Regresión logística binaria con la presencia de mutación en genes candidatos como variable dependiente

\begin{tabular}{|c|c|c|c|c|}
\hline A & OR & IC95\% & $\mathrm{p}$ & $R^{2}$ Nagelkerke \\
\hline Edad basal & 0,962 & 0,879-1,065 & 0,243 & 0,192 \\
\hline IMC basal & 1,018 & $0,838-1,234$ & 0,852 & \\
\hline cLDL basal & 1,023 & $1,012-1,036$ & $<0,001$ & \\
\hline B & OR & IC $95 \%$ & $\mathrm{p}$ & $R^{2}$ Nagelkerke \\
\hline Edad basal & 0,958 & $0,873-1,061$ & 0,379 & 0,213 \\
\hline IMC basal & 1,026 & $0,839-1,25$ & 0,797 & \\
\hline LDL ajustadas por $\mathrm{Lp}(\mathrm{a})$ & 1,024 & $1,013-1,037$ & $<0,001$ & \\
\hline C & OR & IC95\% & $\mathrm{p}$ & $R^{2}$ Nagelkerke \\
\hline Edad basal & 0,961 & $0,880-1,059$ & 0,389 & 0,157 \\
\hline IMC basal & 0,995 & $0,821-1,204$ & 0,959 & \\
\hline Colesterol total basal & 1,017 & $1,008-1,025$ & $<0,001$ & \\
\hline $\mathrm{D}$ & OR & IC95\% & $\mathrm{p}$ & $R^{2}$ Nagelkerke \\
\hline Criterio $1^{\mathrm{a}}$ & 2,332 & $0,822-7,591$ & 0,127 & 0,099 \\
\hline Criterio $2^{\mathrm{b}}$ & 0,735 & $0,039-4,153$ & 0,775 & \\
\hline Criterio $3^{c}$ & 0,324 & $0,026-7,607$ & 0,389 & \\
\hline Criterio 4 & 4,01 & $1,163-18,40$ & 0,011 & \\
\hline
\end{tabular}

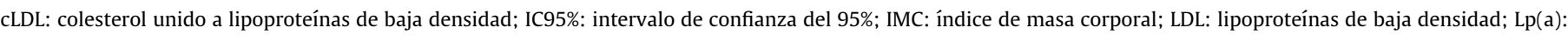
lipoproteína(a); OR: odds ratio.

a Participantes no tratados con concentraciones de cLDL > percentil 95 de la población española en al menos 2 determinaciones.

b Participantes con EC prematura (edad $<55$ años los varones y $<60$ las mujeres).

c Participantes en tratamiento con estatinas los últimos 6 años y cLDL $>130 \mathrm{mg} / \mathrm{dl}$ en al menos 2 determinaciones.

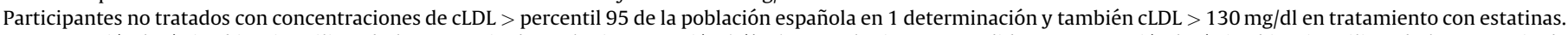

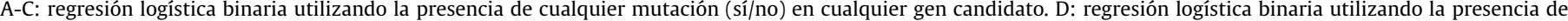
cualquier mutación (sí/no) en el gen $L D L R$.

concentraciones de colesterol total y cLDL significativamente superiores a las de los portadores de mutaciones del gen STAP1 y los clasificados como casos de hiperLp(a) ( $p<0,001$ y $\mathrm{p}<0,001$ respectivamente). Por otra parte, los participantes portadores de mutaciones en el gen STAP1 fueron los que mostraron las concentraciones más bajas de colesterol total y cLDL, inferiores a las de los participantes sin mutaciones en los genes candidatos.

Las mutaciones en el gen $L D L R$ implicaban al $75 \%$ de algunas mutaciones en genes candidatos, en comparación con el 25\% de ellas en los participantes que eran portadores de alguna mutación en el gen

Tabla 5

Número de participantes portadores de una mutación, según los criterios que cumplan

\begin{tabular}{|c|c|c|c|c|c|c|c|c|}
\hline \multicolumn{5}{|c|}{ Participantes que cumplen criterios } & \multirow[t]{3}{*}{ VPP } & \multirow[t]{3}{*}{$\mathrm{VPN}^{*}$} & \multirow[t]{3}{*}{ Sensibilidad* } & \multirow[t]{3}{*}{ Especificidad $^{*}$} \\
\hline Criterio 1 & \multicolumn{2}{|c|}{ Sí $(n=127)$} & \multicolumn{2}{|c|}{ No $(n=128)$} & & & & \\
\hline Mutación & $\overline{\text { Sí }}$ & No & $\overline{\text { Sí }}$ & No & & & & \\
\hline Participantes con mutación & 13 & 114 & 7 & 121 & 0,102 & 0,945 & 0,650 & 0,514 \\
\hline Participantes con una mutación en PCSK9 & 3 & 124 & 1 & 127 & 0,024 & 0,992 & 0,750 & 0,506 \\
\hline Participantes con una mutación en STAP1 & 2 & 125 & 2 & 126 & 0,016 & 0,984 & 0,500 & 0,498 \\
\hline Participantes con mutación & 1 & 20 & 19 & 215 & 0,048 & 0,919 & 0,050 & 0,915 \\
\hline Participantes con una mutación en $L D L R$ & 0 & 21 & 12 & 222 & 0,000 & 0,949 & 0,000 & 0,914 \\
\hline Participantes con una mutación en PCSK9 & 1 & 20 & 3 & 231 & 0,048 & 0,987 & 0,750 & 0,920 \\
\hline Participantes con una mutación en STAP1 & 0 & 21 & 4 & 230 & 0,000 & 0,983 & 0,000 & 0,916 \\
\hline Criterio 3 & \multicolumn{2}{|c|}{ Sí (n=39) } & \multicolumn{2}{|c|}{ No $(n=216)$} & VPP & $\mathrm{VPN}^{*}$ & Sensibilidad* & Especificidad* \\
\hline Participantes con una mutación en STAP1 & 1 & 38 & 3 & 213 & 0,026 & 0,986 & 0,250 & 0,849 \\
\hline Criterio 4 & \multicolumn{2}{|c|}{ Sí $(n=113)$} & \multicolumn{2}{|c|}{ No $(n=142)$} & VPP & $\mathrm{VPN}^{*}$ & Sensibilidad* & Especificidad* \\
\hline Mutación & $\overline{\text { Sí }}$ & No & $\overline{\text { Sí }}$ & No & & & & \\
\hline Participantes con mutación & 10 & 103 & 10 & 132 & 0,088 & 0,930 & 0,500 & 0,562 \\
\hline Participantes con una mutación en $L D L R$ & 9 & 104 & 3 & 139 & 0,080 & 0,979 & 0,750 & 0,572 \\
\hline Participantes con una mutación en PCSK9 & 0 & 113 & 4 & 138 & 0,000 & 0,972 & 0,000 & 0,550 \\
\hline Participantes con una mutación en STAP1 & 1 & 112 & 3 & 139 & 0,009 & 0,979 & 0,250 & 0,553 \\
\hline
\end{tabular}

VPN: valor predictivo negativo; VPP: valor predictivo positivo.

"Respecto a la muestra seleccionada en función de la presencia de al menos 1 criterio. 
PSCK9. En la figura 2 se muestra el porcentaje de mutaciones según los grupos definidos por las concentraciones de cLDL basales. Cuanto mayor es el porcentaje, mayor es el aumento del cLDL: el 0,40\% de los participantes con valores basales de cLDL $<190 \mathrm{mg} / \mathrm{dl}$, el 1,20\% con cLDL basal de $190-220 \mathrm{mg} / \mathrm{dl}$ y un $4,80 \%$ con cLDL basal $>220 \mathrm{mg} / \mathrm{dl}$ presentaban una mutación en genes candidatos. Teniendo en cuenta a los pacientes con una mutación en genes candidatos para la HF más los pacientes con hiperLp(a), casi un 16\% del grupo con criterios de sospecha tenía una enfermedad monogénica.

Se utilizó una regresión logística binaria para estudiar la asociación de los datos clínicos con 2 variables de respuesta: mutación en cualquier gen y mutación en el gen $L D L R$. El análisis mostró que las concentraciones basales de cLDL, el cLDL ajustado por la Lp(a) y el colesterol total tenían una asociación significativa con la presencia (sí/ no) de cualquier mutación en los genes candidatos (odds ratio [OR] = $1,023 ; \mathrm{p}<0,001 ; \mathrm{OR}=1,024 ; \mathrm{p}<0,001 ; \mathrm{OR}=1,017 ; \mathrm{p}<0,001)$ (tabla 4A-C). No obstante, ningún criterio mostró una asociación significativa con la presencia de cualquier mutación en los genes candidatos. La presencia de una mutación en el gen $L D L R$ (sí/no) mostró una asociación significativa con las cifras basales de colesterol total y $\operatorname{cLDL}(\mathrm{OR}=1,009 ; \mathrm{p}=0,010 ; \mathrm{OR}=1,016 ; \mathrm{p}=0,0488)$ y con los criterios de sospecha de HF: concentraciones de cLDL sin tratamiento superiores al percentil 95 en 1 determinación junto con una concentración de cLDL $>130 \mathrm{mg} / \mathrm{dl}$ en tratamiento con estatinas ( $\mathrm{p}=0,011)$ (tabla 4D).

En la tabla 5 se muestra el número de participantes con una mutación en función de los criterios que cumplían, los valores predictivos positivo y negativo y la sensibilidad y la especificidad respecto a la muestra seleccionada por la presencia de al menos 1 criterio. El primer criterio fue el que mostró el valor predictivo positivo más alto $(10,2 \%)$ para detectar mutaciones funcionales en los genes candidatos (genes LDLR, PCSK9 y STAP1), en especial para detectar mutaciones en los genes $L D L R$ y PCSK9 (el 6,3 y el 2,4\%). No obstante, el cuarto criterio fue el que mostró un valor predictivo positivo más alto para detectar mutaciones en el gen $\operatorname{LDLR}(8,0 \%), \mathrm{y}$ mostró en esta muestra seleccionada una especificidad superior a la del primer criterio $(0,510$ y 0,572 respectivamente).

\section{DISCUSIÓN}

Este estudio analiza la frecuencia de mutaciones patógenas en genes candidatos para la HF monogénica en una población con sospecha clínica de HF. De nuestros resultados se puede extraer 3 conclusiones principales. En primer lugar, la concentración de cLDL alta es el principal factor asociado con un diagnóstico genético positivo; segundo, el cLDL alto por sí solo no es lo suficientemente específico para utilizarlo en la identificación de la $\mathrm{HF}$, que requiere un análisis genético, y tercero, debe incluirse la concentración de $\mathrm{Lp}(\mathrm{a})$ en el algoritmo diagnóstico de la HF. Nuestro estudio analiza a más de 4.500 individuos de la cohorte del AWHS, que corresponde a una población sana de mediana edad, y muestra que aproximadamente un 5\% (255 participantes) cumplían los criterios de sospecha diagnóstica de HF, pero solo 16 $(0,4 \%)$ tenían una mutación patógena en los genes LDLR o PCSK9.

La identificación de la HF es una cuestión importante, ya que los portadores de una mutación de HF presentan un aumento sustancial del riesgo de $\mathrm{EC}^{20}$, de modo que el estudio genético permite la identificación de los sujetos con hipercolesterolemia en mayor riesgo ${ }^{5}$. El análisis de los genes candidatos junto con la cuantificación de la $\operatorname{Lp}(\mathrm{a})$ permite la identificación de casi un 16\% de las causas de estos grupos de hipercolesterolemia grave. Nuestros datos coinciden con los estudios publicados anteriormente sobre la prevalencia de la hiperLp(a) como causa de hipercolesterolemia primaria ${ }^{18,45}$ y refuerzan la idea de que la evaluación genética de un paciente con sospecha de HF debe incluir los genes candidatos y la cuantificación de la concentración de $\operatorname{Lp}(\mathrm{a})^{9}$.

El concepto de HF está evolucionando y, posiblemente, con los criterios clínicos actuales, la enfermedad sea un síndrome de hipercolesterolemia grave genética, que a veces es monogénico y otras, poligénico o de base compleja ${ }^{46}$. Este artículo hace referencia a la HF heterocigota, que es la forma más frecuente de la HF con diagnóstico clínico definitivo y la que muestra una asociación más estrecha con la ECV y, por consiguiente, requiere que se establezca más pronto un diagnóstico de presunción.

Tradicionalmente, se ha estimado que la prevalencia de la HF es de $1: 500^{2}$. Sin embargo, estudios posteriores han puesto de manifiesto que la HF clínica probablemente sea más frecuente de lo que se había pensado, con una prevalencia de 1:217 en el estudio Copenhagen General Population ${ }^{3}$. En nuestro estudio, se observó que 255 participantes, de un total de 4.514 individuos estudiados, cumplían los criterios de sospecha de HF, lo cual indica que 1:18 cumplían los criterios de sospecha de HF. De estos 255 participantes, 20 tenían una variante rara en los genes $L D L R$, PCSK9 o STAP1, lo cual apuntaría a una prevalencia de HF de 1:226. De un total de 20 participantes con variantes raras en genes candidatos, 12 tenían una mutación en el gen $L D L R$, 4 la tenían en el gen PCSK9 y 4 tenían una variante en el gen STAP1.

Según lo indicado por estudios recientes ${ }^{16,17,47}$, el papel del gen STAP1 no se ha asociado claramente con el fenotipo de HF y, por este motivo, nosotros recalculamos la prevalencia de la HF considerando solo a los portadores de mutaciones en los genes LDLR y PCSK9. Con este criterio, la prevalencia disminuiría de 1:226 a 1:282. En el presente estudio, hemos puesto de manifiesto que los portadores de $L D L R$ FH presentan el fenotipo de HF extrema, tal como se había descrito anteriormente ${ }^{48,49}$. Por consiguiente, si tenemos en cuenta tan solo a los portadores del gen $L D L R$, la prevalencia de la HF se reduce de 1:226 a 1:376.

En el análisis de secuenciación de los genes $L D L R, A P O B, P C S K 9$, APOE, STAP1 y LDLRAP1, se identificaron 5.280 variantes, pero solo 16 de ellas fueron posiblemente patógenas o patógenas según el análisis in silico: a) 11 variantes patógenas en el gen $L D L R$ que ya estaban asociadas con la $\mathrm{HF}^{34-40}$; b) 1 variante patógena en el gen PCSK9 (c.60_65dupGCTGCT), que tiene una frecuencia $<0,5 \%$ de la población general y se ha clasificado como patógena mediante el análisis bioinformático; sin embargo, serán necesarios nuevos estudios para investigar la funcionalidad de esta variante; $c$ ) 1 variante rara en el gen $A P O B(c .10621 \mathrm{~A}>\mathrm{G})$; esta variante que produce el cambio de aminoácido p.(Ile3515Val) en la proteína madura está situado en el dominio beta 2 de la apolipoproteína $\mathrm{B}$, y las herramientas de predicción computacionales y los análisis de conservación indican que esta variante no tendrá repercusión en la función de la proteína; además, las herramientas de ayuste computacionales indican que esta variante no tendría repercusiones en el ayuste del $\mathrm{ARN}^{50}$; d) 3 variantes raras en el gen STAP1, 1 de ellas situada en el 5'UTR (c.-60A $>G$ ) y 2 en regiones de codificación (c.619G $>$ A y c.803T $>$ C) que producen cada una un cambio de aminoácido, es decir, p.(Ile268Thr) y p.(Asp207Asn) respectivamente; todas estas variantes se han clasificado como patógenas mediante el análisis bioinformático, pero de ninguna de ellas se ha establecido antes una asociación con la HF, y serán necesarios más estudios sobre el papel del gen STAP1 en el fenotipo de la HF, ya que en estudios previos se ha descrito a participantes que son portadores de mutaciones del gen STAP1 y presentan unas concentraciones normales de colesterol total y cLDL y una asociación incompleta con la $\mathrm{HF}^{16,17,51}$; e) 2 variantes raras en el gen LDLRAP1, 1 de ellas situada en la región intrónica (c.748-7C $>\mathrm{G}$ ), que podría producir un ayuste alternativo, y otra situada en una región de codificación (c.605C >G), que conllevaría el cambio de aminoácido p.(Ser202Cys); esta variante se ha clasificado como patógena mediante el análisis bioinformático, pero el participante era portador de esta variante en heterocigosis, $\mathrm{y}$ 
ello no explicaría el fenotipo de $\mathrm{HF}$, y f) 3 variantes missense raras en el gen $A P O E, 2$ de ellas (c.460C $>$ A y c.487C $>$ T) descritas como patógenas por Clin $\operatorname{Var}^{52}$ y asociadas a la hiperlipoproteinemia de tipo III $^{43,44}$, pero no a la HF.

Nuestros resultados muestran una asociación significativa de las concentraciones de cLDL con la presencia de una mutación causal en genes candidatos. Aunque en nuestra muestra, procedente de una población laboral, la EC fue escasa y mostró el más bajo valor predictivo positivo de las mutaciones, los participantes con cifras de cLDL sin tratamiento $>220 \mathrm{mg} / \mathrm{dl}$ y aquellos con cLDL $>130 \mathrm{mg} / \mathrm{dl}$ a pesar del tratamiento con estatinas mostraron una asociación significativa con la presencia de una mutación patógena. En ellos, la probabilidad de hallar una mutación causal en un gen candidato fue 4 veces superior a la de los pacientes que cumplían los demás criterios de sospecha de HF. En el futuro, la disminución progresiva de los costes del análisis del ADN probablemente facilite la aplicación de programas universales de detección sistemática en la población. Sin embargo, dados sus costes actuales, se hace necesario seleccionar a los candidatos a las pruebas genéticas. Nuestros resultados indican que no solo las altas concentraciones de cLDL sin tratamiento son un buen marcador de la HF en la población general, sino que la combinación de estos valores con concentraciones altas de cLDL a pesar del tratamiento con estatinas podría ser un mejor predictor de la HF. Además, los participantes con cifras de cLDL altas sin tratamiento y cifras altas pese al tratamiento con estatinas fueron los que mostraron mayores porcentajes de mutaciones en $\operatorname{LDLR}(7,96 \%)$, y estos participantes mostraron también un fenotipo de HF más extremo.

El porcentaje de mutaciones en genes candidatos muestra grandes diferencias, con valores que van del $55,6 \%$ cuando se dispone de información de antecedentes de un patrón monogénico familiar de hipercolesterolemia ${ }^{8}$ a menos del $2 \%$ si se usa exclusivamente la concentración de LDL $>190 \mathrm{mg} / \mathrm{dl}^{20}$. Nuestro estudio es plenamente coherente con el concepto de que una concentración de cLDL alta por sí sola, sin información de antecedentes familiares de hipercolesterolemia grave, permite la identificación de un pequeño porcentaje de pacientes con HF.

\section{Limitaciones}

Nuestro estudio tiene ciertas limitaciones. En primer lugar, el AWHS es una cohorte con grandes prevalencias de varones, obesidad, hipertensión e hipercolesterolemia, y ello puede hacer que no sea representativa de la población general. Sin embargo, dado que se trata de una población relativamente joven, no habrá un sesgo en la prevalencia de mutaciones de HF. En segundo lugar, se presentan algunas mutaciones, como la c.743G >A en PCSK9 y la c.10621A $>$ G en $A P O B$, que tienen una significación incierta. No obstante, ambas se han descrito como neutras o benignas mediante el análisis bioinformático y la base de datos ClinVar, por lo que no hay datos suficientes para clasificarlas como variantes patógenas. Los análisis de secuenciación del gen $A P O B$ incluyeron solo los exones 26 y 29, mientras que la secuenciación del gen $A P O B$ completo podría mostrar otras variantes como causa del fenotipo de HF. Sin embargo, la hipercolesterolemia debida a defectos del gen $A P O B$ requeriría que la proteína tuviera una unión defectuosa con el receptor de LDL, ya que las mutaciones que causan solo una menor expresión o un plegado inadecuado de la ApoB causarían hipocolesterolemia. Así pues, es de prever que las variantes causantes de HF estén situadas en la región de codificación del dominio de unión de la $A p o B$ (en los exones 26 y 29). De hecho, la mayoría de las mutaciones del gen $A P O B$ descritas como causa de HF se han identificado en el exón $26^{49}$. Por último, las mutaciones posiblemente patógenas de PCSK9 (c.60_65dupGCTGCT) y STAP1 (c.-60A >G, c.619G $>$ A y c.803T $>$ C) requerirán nuevos estudios para disponer de una perspectiva más amplia respecto a su papel en el fenotipo de HF.

\section{CONCLUSIONES}

El presente estudio analiza el valor predictivo positivo de los criterios diagnósticos clínicos para la HF. En nuestro estudio se incluyó a un total de 4.514 individuos de la cohorte del AWHS, formada por una población de mediana edad sana. Cumplían los criterios diagnósticos para la sospecha clínica de HF 255 individuos, y 16 de ellos $(6,27 \%)$ presentaban mutaciones en los genes $L D L R$ y PCSK9, lo cual corresponde a una prevalencia de HF de 1:282 en esta población. Además, a 24 participantes $(9,41 \%)$ se les diagnosticó una hiperLp(a), lo cual permitió identificar casi un $16 \%$ de la etiología de estos grupos de hipercolesterolemia grave. Las concentraciones de cLDL sin tratamiento y los valores de cLDL altos a pesar del tratamiento con estatinas mostraron una asociación significativa con la presencia de mutaciones en los genes candidatos. Estos resultados indican que la combinación de un cLDL alto sin tratamiento y valores de cLDL altos a pesar del tratamiento con estatinas podría ser un primer paso, aunque no el único, para el cribado poblacional de la HF.

\section{FINANCIACIÓN}

Este trabajo contó con el apoyo de subvenciones del Gobierno de Aragón, B14-7R, España y del Ministerio de Economía y Competitividad de España PI15/01983, PI18/01777 y CIBERCV. Estos proyectos son cofinanciados por el Instituto de Salud Carlos III y el Fondo Europeo de Desarrollo Regional (FEDER) de la Unión Europea "Una manera de hacer Europa». CIBERCV es un proyecto del Instituto de Salud Carlos III.

\section{CONFLICTO DE INTERESES}

Los autores declaran no tener conflictos de intereses.

\section{¿QUÉ SE SABE DEL TEMA?}

- La HF es un trastorno genético caracterizado por altas concentraciones plasmáticas de colesterol total y cLDL y alto riesgo de ECV.

- Se ha demostrado que los criterios clínicos muestran una gran asociación con el diagnóstico genético.

- Sin embargo, un 20-40\% de los pacientes con el fenotipo de HF no presentan una mutación en los genes candidatos.

- La European Atherosclerosis Society ha recomendado emplear unos nuevos criterios diagnósticos para la sospecha de HF, que no han sido validados aún.

\section{¿QUÉ APORTA DE NUEVO?}

- La prevalencia de la HF en España es de 1:282.

- Tan solo un 6,27\% de los participantes con sospecha de HF presentaban mutaciones funcionales en los genes LDLR y PCSK9.

- A un total del 9,41\% de los participantes con sospecha de HF se les diagnosticó una hiperlipoproteinemia(a).

- La combinación de una concentración de cLDL alta sin tratamiento y valores de cLDL altos a pesar del tratamiento con estatinas es el mejor predictor de un resultado positivo para una mutación de HF. 


\section{ANEXO. MATERIAL ADICIONAL}

Se puede consultar material adicional a este artículo en su versión electrónica disponible en https://doi.org/10.1016/j.recesp. 2020.05.034

\section{BIBLIOGRAFÍA}

1. Civeira F. International Panel on Management of Familial Hypercholesterolemia. Guidelines for the diagnosis and management of heterozygous familial hypercholesterolemia. Atherosclerosis. 2004;173:55-68.

2. Goldstein JL, Brown MS. The LDL receptor. Arterioscler Thromb Vasc Biol. 2009;29:431-438.

3. Benn M, Watts GF, Tybjærg-Hansen A, Nordestgaard BG. Mutations causative of familial hypercholesterolaemia: screening of 98098 individuals from the Copenhagen General Population Study estimated a prevalence of 1 in 217. Eur Heart J. 2016;37:1384-1394

4. Besseling J, Hovingh GK, Huijgen R, Kastelein JJP, Hutten BA. Statins in Familial Hypercholesterolemia: Consequences for Coronary Artery Disease and All-Cause Mortality. J Am Coll Cardiol. 2016;68:252-260.

5. Perez-Calahorra S, Laclaustra M, Marco-Benedí V, et al. Effect of lipid-lowering treatment in cardiovascular disease prevalence in familial hypercholesterolemia. Atherosclerosis. 2019;284:245-252.

6. Nordestgaard BG, Chapman MJ, Humphries SE, et al. Familial hypercholesterolaemia is underdiagnosed and undertreated in the general population: guidance for clinicians to prevent coronary heart disease: consensus statement of the European Atherosclerosis Society. Eur Heart J. 2013;34:3478-3490.

7. Austin MA, Hutter CM, Zimmern RL, Humphries SE. Genetic causes of monogenic heterozygous familial hypercholesterolemia: a HuGE prevalence review. Am J Epidemiol. 2004;160:407-420.

8. Civeira F, Ros E, Jarauta E, et al. Comparison of genetic versus clinical diagnosis in familial hypercholesterolemia. Am J Cardiol. 2008;102:1187-11931193.e1.

9. Berberich AJ, Hegele RA. The complex molecular genetics of familial hypercholesterolaemia. Nat Rev Cardiol. 2019;16:9-20.

10. Chan DC, Pang J, Hooper AJ, et al. A Comparative Analysis of Phenotypic Predictors of Mutations in Familial Hypercholesterolemia. J Clin Endocrinol Metab. 2018;103:1704-1714.

11. Mach F, Baigent C, Catapano AL, et al. 2019 ESC/EAS Guidelines for the management of dyslipidaemias: lipid modification to reduce cardiovascular risk. Eur Heart J. 2020;41:111-188.

12. Soria LF, Ludwig EH, Clarke HR, Vega GL, Grundy SM, McCarthy BJ. Association between a specific apolipoprotein B mutation and familial defective apolipoprotein B-100. Proc Natl Acad Sci USA. 1989;86:587-591.

13. Abifadel M, Varret M, Rabès J-P, et al. Mutations in PCSK9 cause autosomal dominant hypercholesterolemia. Nat Genet. 2003;34:154-156.

14. Cenarro A, Etxebarria A, de Castro-Orós I, et al. The p.Leu167del Mutation in APOE Gene Causes Autosomal Dominant Hypercholesterolemia by Down-regulation of LDL Receptor Expression in Hepatocytes. J Clin Endocrinol Metab. 2016;101:2113-2121.

15. Fouchier SW, Dallinga-Thie GM, Meijers JCM, et al. Mutations in STAP1 are associated with autosomal dominant hypercholesterolemia. Circ Res. 2014; 115:552-555.

16. Blanco-Vaca F, Martín-Campos JM, Pérez A, Fuentes-Prior P. A rare STAP1 mutation incompletely associated with familial hypercholesterolemia. Clin Chim Acta. 2018;487:270-274.

17. Lamiquiz-Moneo I, Restrepo-Córdoba MA, Mateo-Gallego R, et al. Predicted pathogenic mutations in STAP1 are not associated with clinically defined familial hypercholesterolemia. Atherosclerosis. 2019;292:143-151.

18. Meriño-Ibarra E, Puzo J, Jarauta E, et al. Hyperlipoproteinaemia(a) is a common cause of autosomal dominant hypercholesterolaemia. J Inherit Metab Dis. 2007:30:970-977.

19. Farnier M, Civeira F, Descamps O; FH expert working group. How to implement clinical guidelines to optimise familial hypercholesterolaemia diagnosis and treatment. Atheroscler Suppl. 2017:26:25-35.

20. Khera AV, Won H-H, Peloso GM, et al. Diagnostic Yield and Clinical Utility of Sequencing Familial Hypercholesterolemia Genes in Patients With Severe Hypercholesterolemia. J Am Coll Cardiol. 2016;67:2578-2589.

21. Casasnovas JA, Alcaide V, Civeira F, et al. Aragon Workers' Health Study-Design and Cohort Description. BMC Cardiovasc Disord. 2012;12:45.

22. Gómez-Gerique JA, Gutiérrez-Fuentes JA, Montoya MT, et al.[Lipid profile of the Spanish population: the DRECE (diet and risk of cardiovascular disease in Spain) study. DRECE study group]. Med Clin (Barc). 1999;113:730-735.

23. Grundy SM, Stone NJ, Bailey AL, et al. 2018 AHA/ACC/AACVPR/AAPA/ABC/ACPM/ ADA/AGS/APhA/ASPC/NLA/PCNA Guideline on the Management of Blood Cholesterol: A Report of the American College of Cardiology/American Heart Association Task Force on Clinical Practice Guidelines. J Am Coll Cardiol. 2019;73:e285-e350.

24. Rhoads GG, Dahlen G, Berg K, Morton NE, Dannenberg AL. Lp(a) lipoprotein as a risk factor for myocardial infarction. JAMA. 1986;256:2540-2544.
25. Dahlén GH, Weinehall L, Stenlund H, et al. Lipoprotein(a) and cholesterol levels act synergistically and apolipoprotein A-I is protective for the incidence of primary acute myocardial infarction in middle-aged males. An incident case-control study from Sweden. J Intern Med. 1998;244:425-430.

26. Vaser R, Adusumalli S, Leng SN, Sikic M, Ng PC. SIFT missense predictions for genomes. Nat Protoc. 2016;11:1-9.

27. Adzhubei IA, Schmidt S, Peshkin L, et al. A method and server for predicting damaging missense mutations. Nat Methods. 2010;7:248-249.

28. Schwarz JM, Rödelsperger C, Schuelke M, Seelow D. MutationTaster evaluates disease-causing potential of sequence alterations. Nat Methods. 2010;7:575-576.

29. Bendl J, Musil M, Štourač J, Zendulka J, Damborský J, Brezovský J. PredictSNP2: A Unified Platform for Accurately Evaluating SNP Effects by Exploiting the Different Characteristics of Variants in Distinct Genomic Regions. PLoS Comput Biol. 2016;12:e1004962.

30. Choi Y, Sims GE, Murphy S, Miller JR, Chan AP. Predicting the functional effect of amino acid substitutions and indels. PLoS ONE. 2012;7:e46688.

31. 1000 Genomes Project Consortium, Abecasis GR, Auton A, et al. An integrated map of genetic variation from 1,092 human genomes. Nature. 2012;491:56-65.

32. Lek M, Karczewski KJ, Minikel EV, et al. Analysis of protein-coding genetic variation in 60,706 humans. Nature. 2016;536:285-291.

33. R Core Team. R: A language and environment for statistical computing. R Foundation for Statistical Computing, Vienna, Austria. 2018. Disponible en: https://www. r-project.org/. Consultado 29 Abr 2019.

34. Cenarro A, Jensen HK, Casao E, et al. Identification of recurrent and novel mutations in the LDL receptor gene in Spanish patients with familial hypercholesterolemia. Mutations in brief no 135 Online Hum Mutat. 1998:11:413.

35. Mozas P, Cenarro A, Civeira F, Castillo S, Ros E, Pocovi M. Mutation analysis in 36 unrelated Spanish subjects with familial hypercholesterolemia: identification of 3 novel mutations in the LDL receptor gene. Hum Mutat. 2000;15:483-484.

36. Tichý L, Freiberger T, Zapletalová P, Soška V, Ravčuková B, Fajkusová L. The molecular basis of familial hypercholesterolemia in the Czech Republic: spectrum of LDLR mutations and genotype-phenotype correlations. Atherosclerosis 2012;223:401-408

37. Etxebarria A, Palacios L, Stef M, et al. Functional characterization of splicing and ligand-binding domain variants in the LDL receptor. Hum Mutat. 2012;33:232-243.

38. Bertolini S, Pisciotta L, Rabacchi C, et al. Spectrum of mutations and phenotypic expression in patients with autosomal dominant hypercholesterolemia identified in Italy. Atherosclerosis. 2013;227:342-348.

39. Etxebarria A, Benito-Vicente A, Palacios L, et al. Functional characterization and classification of frequent low-density lipoprotein receptor variants. Hum Mutat. 2015;36:129-141.

40. Brænne I, Kleinecke M, Reiz B, et al. Systematic analysis of variants related to familial hypercholesterolemia in families with premature myocardial infarction. Eur J Hum Genet. 2016;24:191-197.

41. VCV000265916.5 - ClinVar - NCBI. Disponible en: https://www.ncbi.nlm.nih.gov/ clinvar/variation/265916/. Consultado 13 May 2020.

42. Garcia UG, Vicente AB, Etxebarria A, et al. The leucine stretch length of PCSK9 signal peptide and its role in development of autosomal dominant hypercholesterolaemia: Unravelling the activities of P.LEU23DEL and P.LEU22_LEU23DUP variants. Atherosclerosis. 2017;263:e37. http://doi.org/10.1016/j.atherosclerosis.2017.06.138.

43. Pocovi M, Cenarro A, Civeira F, et al. Incomplete dominance of type III hyperlipoproteinemia is associated with the rare apolipoprotein E2 (Arg136- >Ser) variant in multigenerational pedigree studies. Atherosclerosis. 1996;122:33-46.

44. Hsia SH, Connelly PW, Hegele RA. Restriction isotyping of apolipoprotein E R145C in type III hyperlipoproteinemia. J Investig Med. 1995;43:187-194.

45. Langsted A, Kamstrup PR, Benn M, Tybjærg-Hansen A, Nordestgaard BG. High lipoprotein(a) as a possible cause of clinical familial hypercholesterolaemia: a prospective cohort study. Lancet Diabetes Endocrinol. 2016;4:577-587.

46. Masana L, Ibarretxe D, Rodríguez-Borjabad C, et al. Toward a new clinical classification of patients with familial hypercholesterolemia: One perspective from Spain. Atherosclerosis. 2019;287:89-92.

47. Loaiza N, Hartgers ML, Reeskamp LF, et al. Taking One Step Back in Familial Hypercholesterolemia: STAP1 Does Not Alter Plasma LDL (Low-Density Lipoprotein) Cholesterol in Mice and Humans. Arterioscler Thromb Vasc Biol. 2020;40:973-985

48. García-Alvarez I, Castillo S, Mozas P, et al. Differences in clinical presentation between subjects with a phenotype of familial hypercholesterolemia determined by defects in the LDL-receptor and defects in Apo B-100. Rev Esp Cardiol. 2003;56:769-774.

49. De Castro-Orós I, Pocoví M, Civeira F. The genetic basis of familial hypercholesterolemia: inheritance, linkage, and mutations. Appl Clin Genet. 2010:3:53-64.

50. VCV000630672.1 - ClinVar - NCBI. Available at: https://www.ncbi.nlm.nih.gov/ clinvar/variation/630672/. Consultado 9 Ago 2019.

51. Amor-Salamanca A, Castillo S, Gonzalez-Vioque E, et al. Genetically Confirmed Familial Hypercholesterolemia in Patients With Acute Coronary Syndrome. J Am Coll Cardiol. 2017;70:1732-1740.

52. VCV000017850.1 - ClinVar - NCBI. Available at: https://www.ncbi.nlm.nih.gov/ clinvar/variation/17850/. Consultado 9 Ago 2019. 